\title{
Behavior of the Reverse Flow in Front of the Leading Flame Edge Spreading over Fuel-Soaked Sand in an Air Stream
}

\author{
TAKUJI SUZUKI, MASAAKI KAWAMATA and KINYA MATSUMOTO \\ Department of Mechanical Engineering \\ Ibaraki University, Ibaraki, Japan
}

\section{TOSHISUKE HIRANO}

Department of Reaction Chemistry

The University of Tokyo, Tokyo, Japan

\section{ABSTRACT}

The behavior of the reverse flow in front of the leading flame edge spreading over kerosene-soaked sand in an air stream has been examined using a few flow visualization techniques, and the role of the reverse flow in the flame spread is discussed. In a wide range of the free stream velocities $U$ from 30 to $210 \mathrm{~cm} / \mathrm{s}$, a stable reverse flow region in front of the leading flame edge was observed clearly, and its horizontal dimension was found to be almost independent of $U$. As $U$ increases, the velocity of the reverse flow increases. The reverse flow takes an important role in the stable flame spread in an pposed aix stream, although it has no appreciable effect on the flame spread rate. The reverse flow provides a slow gas stream region, through which gasified fuel as well as heat from the reaction zone would be transferred in the upstream direction.

KEYWORDS: Liquid combustion, porous solid, flame spread, reverse flow, heat and mass transfer.

\section{INTRODUCTION}

For the prediction of the fire growth over porous materials soaked with spilled combustible iliquids, knowledge of the flame spread mechanisms over porous solids soaked with combustible liquids seems to be indispensable. However, there are very few available data on the flame spread over combustible porous solids (1)-(4), although the flame spread over single component liquid or solid combustibles has been examined in a number of previous studies $(5),(6)$. In a few previous studies, the flame spread over crude oil siudge has been examined $(7),(8)$. Since the crude oil. Sludge is a nonfluid multicomponent combustible with volatile components, the results of those studies can be useful. for understanding the flame spread mechanisms over porous solids soaked with combustibie liq- 
uids. Nevertheless, insufficient information j.s given on the dependence of flame spread on solid or combustible liquid characteristics.

Most of the studies on the flame spread over the surface of combustible liquids or solids have concerned with the phenomena in a quiescent atmosphere. However, most actual fixes have occurred in windy conditions which must significantly affect the flame behavior (9), (10). Therefore, knowledge of the flame spread in an air stream is necessary for the hazard assessment of actual Eires.

In our previous study (10), the flame spread over kerosene-soaked sand in an opposed air stream has been examined to explore the effects of the air stream on the flame spread mechanisms. It was pointed out that the stability of the leading flame edge associated with the aerodynamic structure near leading flame edge is necessary for stable flame spread in an opposed air stream. However, the aerodynamic structure revealed in this study is insufficient for a discussion of the process of heat transfer and behavior of gasified fuel, both of which are closely related to the flame spread mechanisms.

In the present study, therefore, in order to explore the flame spread mechanisms to a further extent, the behaviox of the reverse flow in front of the leading flame edge spreading ovex kerosene-soaked sand in an air stream has been examined in detail using a few flow visualization techniques, and the role of the reverse flow in the flame spread is discussed.

\section{EXPERTMENTAL}

A schematic diagram of the experimental apparatus is shown in Fig. 1. A tray of $60 \mathrm{~cm}$ long, $12 \mathrm{~cm}$ wide, and $1 \mathrm{~cm}$ deep was used for the flame spread experiments. The tray was placed in a temperature control bath and a flat plate was set: to be flush with the tray brim, where the distance from the leading edge of the flat plate to the brim of the tray was 30 cm. The tray with the flat plate was set up in the test section of a wind

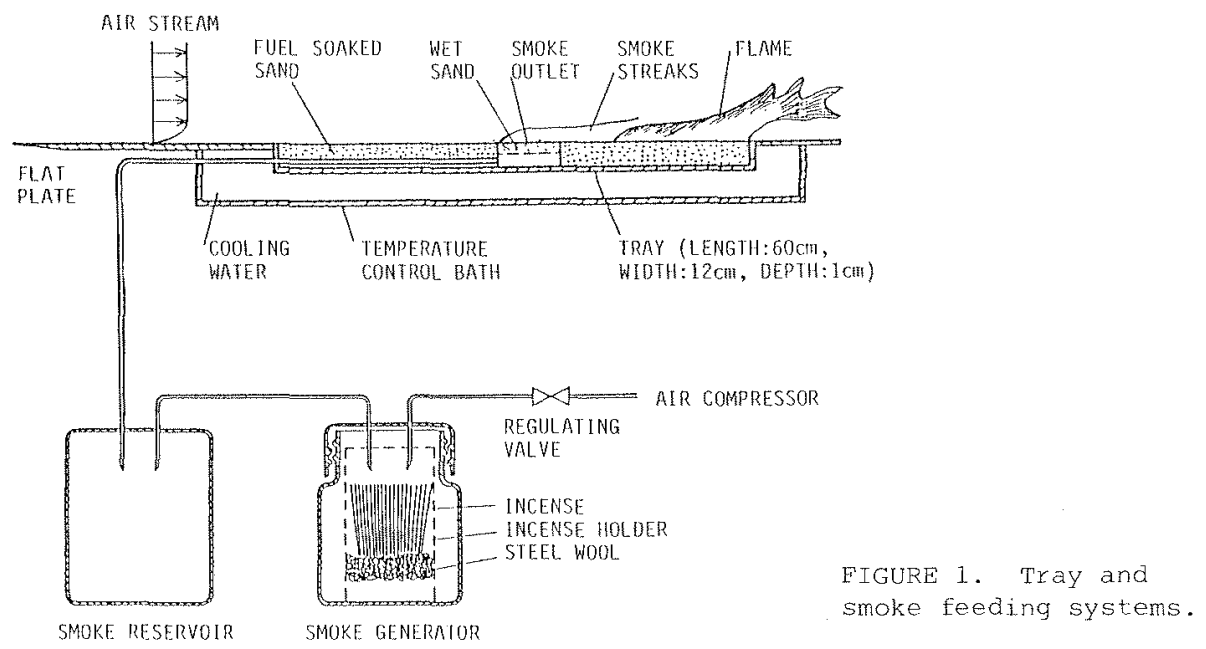


tunnel with a $60 \mathrm{~cm} x 45 \mathrm{~cm}$ outiet, where the air stream was uniform and its turbulence intensity was less than $1 \%$ (10).

In the present experiments, the sand soaked with kerosene at a subflash temperature was used as a representative example of combustible porous soljas. In general, aspects of the flame spread over a porous solid soaked with combustible liquid may be considered to depend largely on the properties of the porous solid. However, only a little difference could be found in the characteristics of flame spread over decane-soaked glass and lead bead layers in the range of bead diameter less than 0.2 $\mathrm{cm}$ (4). Therefore, it is expected that the flame spread in an actual case can be interpreted on the basis of the results obtained in the present study using fine sand. The sand was sieved with 60-mesh and 100-mesh screens, and the mean grain size was $0.022 \mathrm{~cm}$. The density of the sand grains was $2.68 \mathrm{~g} / \mathrm{cm}^{3}$ and the pore volume of the sand was about $0.32 \mathrm{~cm}^{3} / 9$ (46 Vol. \%). Kerosene ( $f$ lash point: about $50{ }^{\circ} \mathrm{C}$ ) was supplied to fill the pore volume of the sand.

As the velocity distribution of the air stream over the surface of the fuel soaked sand must be closely related to the mode of flame spread, profiles of the mean velocity and turbulence intensity across the boundary layer over the sand surface were examined in our previous study (10). In the representative cases when the free stream velocities U were 30, 70, 130, and $2.10 \mathrm{~cm} / \mathrm{s}$, characteristics of the boundary layers at a representative point, where the distance $x$ along the sand surface from the leading edge of the flat plate was $80 \mathrm{~cm}$, are shown in Table 1 . Since the boundary layers were formed on the rough surface and the turbulence intensity of the free stream was about $3 \%$, the characteristics in the transition region appeared even for small Reynolds number.

The tray was filled with the kerosene-soaked sand and its surface was flattened with a trowel. The initial sand temperature T, was controlled to a predetermined value by adjusting the bath temperature. The sand was ignited near the downstream end of the tray by burning a cotton string soaked with kerosene.

The flow field in front of the spreading flame was visualized by feeding incense smoke from the upstream sand surface into the boundary layer of the air stream as show in Fig. 1. The smoke generated in the smoke generator was supplied to the smoke feeder instal led in the middle of the tray and fed into the boundary layer through slightly wet sand on a mesh. The behavior of the spreading flame and the smoke streaks were examined from photographs taken with a motor-driven $35 \mathrm{~mm}$ camera (speed: 4 flames/s) or a high speed video camera (speed: 200 Erames/s, exposure: $1 / 2500 \mathrm{~s})$. The smoke streaks were illuminated using a high pressure mercury vapor lamp of $250 \mathrm{~W}$.

\begin{tabular}{|c|c|c|c|}
\hline $\mathrm{U}, \mathrm{cm} / \mathrm{s}$ & $\mathrm{Re}$ & $\delta, \mathrm{cm}$ & $\delta^{*}, \mathrm{~cm}$ \\
\hline 30 & $1.6 \times 10^{4}$ & 2.4 & 0.48 \\
\hline 70 & $3.6 \times 10^{4}$ & 2.0 & 0.36 \\
\hline 130 & $6.8 \times 10^{4}$ & 1.8 & 0.32 \\
\hline 210 & $1.1 \times 10^{5}$ & 1.5 & 0.26 \\
\hline
\end{tabular}

TABLE 1. Characteristics of the boundary layers at a representative point $x=80 \mathrm{~cm}$ for typical free stream velocities. Re: Reynolds number based on $x$ and $u$, $\delta$ : boundary layer thickness, $\delta *$ : displacement thickness. 
The aspects of the reverse flow in front of the leading flame edge could be recorded on schlieren photographs, which were taken using a schlieren system composed of a stroboscope, two concave mixrors of $10 \mathrm{~cm}$ in diameter (focal length: $100 \mathrm{~cm}$ ), a knife edge, and a motor-driven $35 \mathrm{~mm}$ camera or a high speed video camera.

\section{RESULTS AND DISCUSSION}

Aspects of reverse flow region

After ignition near the downstream end of the tray, a blue leading flame edge followed by a luminous yellow zone is observed to move in an opposed aix stream. The flame size in the longitudinai direction tair stream direction) increases as the flame spreads over the sand surface. However, no appreciable changes in the aspects near the leading flame edge can be observed during its spread. As the free stream velocity $U$ increases, the flame near its leading edge approaches the sand surface and the configuration of the flame fax from its leading edge becomes wavy. Except for unstable spread, the flame spreads at an almost constant rate. The variations of the flame spread rate $V_{f}$ with $u$ were examined previously for typical initial temperatures $\mathrm{T}_{i}$ of kerosene-soaked sand (10).

A reverse flow region was found to be formed on the sand surface in front of the leading flame edge. The existence of the reverse flow region could be confirmed by observing the flow field visualized with naturally generated vapor mist in Eront of the leading flame edge at a higher free
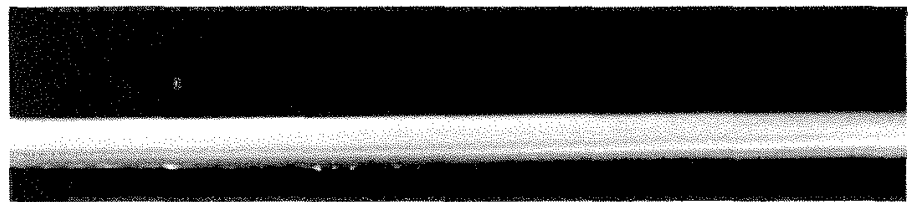

(a) Smoke streaks before flame spread starts.

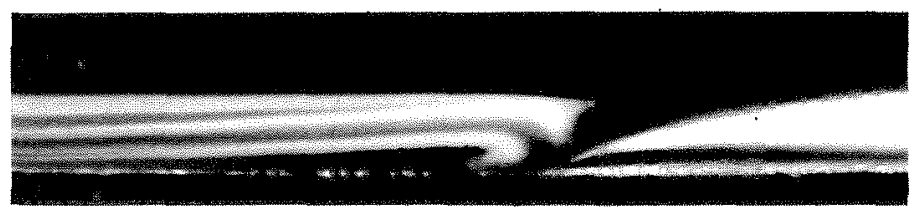

(b) Smoke streaks and leading flame edge $(t=0)$.
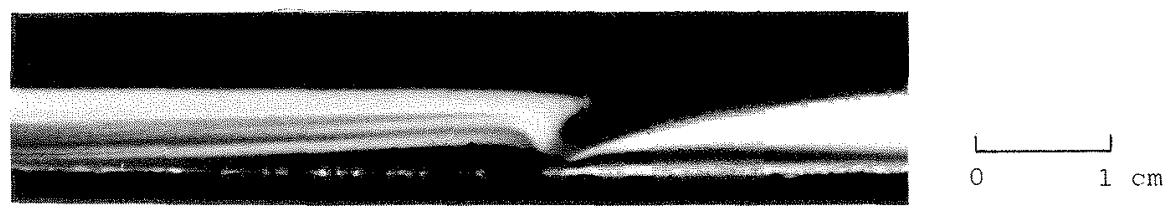

(c) Smoke streaks and leading flame edge $(t=0.25 \mathrm{~s})$.

FIGURE 2. Photographs of smoke streaks and the leading flame edge for a typical free stream velocity. t: time after the state shown in (b) was taken. $\mathrm{U}=70 \mathrm{~cm} / \mathrm{s}, \mathrm{x}=80 \mathrm{~cm}, \mathrm{~T}_{i}=20^{\circ} \mathrm{C}$, exposure: $1 / 125 \mathrm{~s}$. 
stream velocity. In order to examine the aspects of the reverse flow region, the flow field ahead of the spreading flame was visualized by feeding smoke into the boundary layer on the sand surface. Typical photographs (original:color prints) of smoke streaks with and without spreading flame are shown in Fig. 2. Photograph (a) indicates smoke streaks on the sand surface before the flame spread starts. It is found that air in the boundary layer flows along the sand surface. Photographs (b) and (c) indicate formation of a reverse flow in front of the leading flame edge. In this case, the leading flame edge was at $x=80$ $\mathrm{cm}$, where $\mathrm{x}$ is the horizontal distance from the leading edge of the flat plate to that of the spreading flame. The region where smoke streaks vanish, probably due to smoke particle vaporization, was assumed to correspond to the temperature increasing region near the flame zone.

A stable reverse flow region was observed clearly in the wide range of $\mathrm{U}$ from 30 to $210 \mathrm{~cm} / \mathrm{s}$ and the aspects of the reverse flow region were examined. Typical photographs of smoke streaks with a spreading flame and the illustrations representing the phenomena inferred from the photographs axe shown in Eig. 3. As the free stream velocity increases, the flame just behind the leading edge approaches the sand surface and the vertical distance from the sand surface to top edge of the reverse
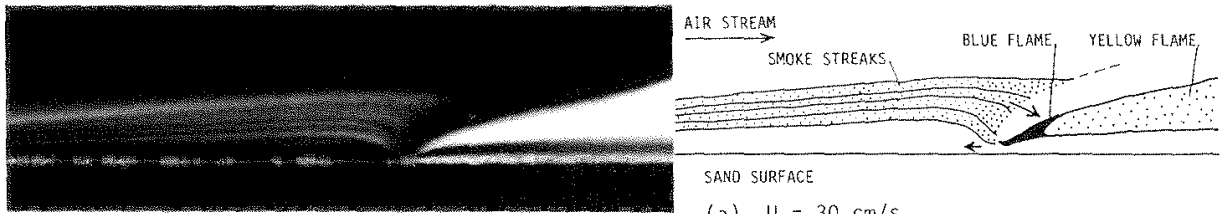

SANO SURFACE

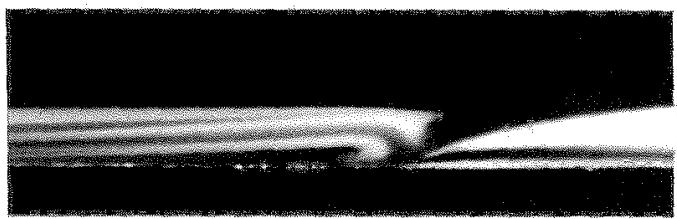

(a) $U=30 \mathrm{~cm} / \mathrm{s}$
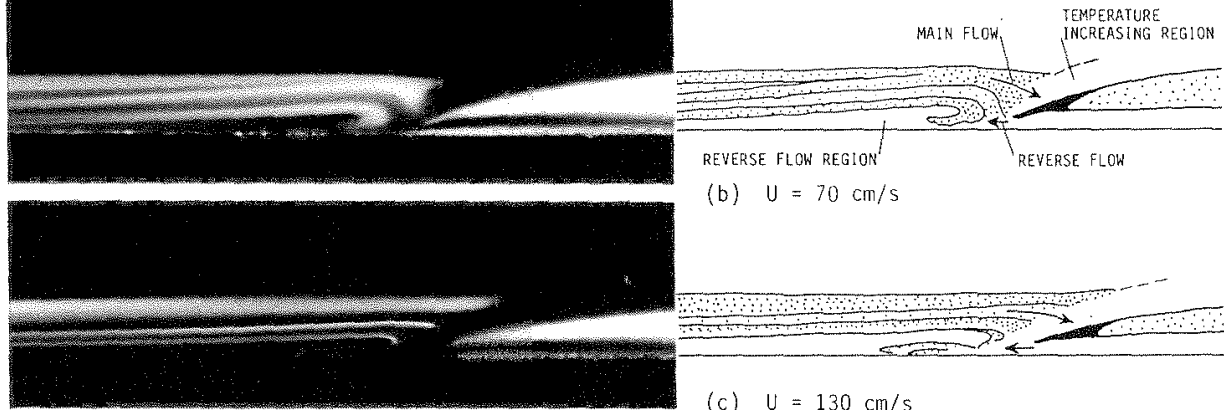

(b) $\mathrm{U}=70 \mathrm{~cm} / \mathrm{s}$
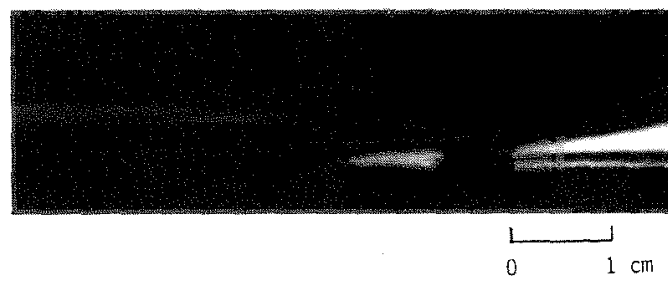

(c) $\mathrm{U}=130 \mathrm{~cm} / \mathrm{s}$

FIGURE 3. Photographs of smoke streaks and the leading flame edge for typical free stream velocities, and illustrations of the phenomena. $\mathrm{x}=80 \mathrm{~cm}, \mathrm{~T}_{i}=20^{\circ} \mathrm{C}$, exposure: $1 / 125 \mathrm{~s}$. 
flow region decreases. For a higher free stream velocity, details of the reverse flow are seen to be visualized with the mist that generates in front of the leading flame edge (see Fig. 3 (d)). In the range of larger values of $\mathrm{U}$, smoke streaks become obscure, although the existence of the reverse flow could be confirmed. The movements of smoke streaks and a generated mist were examined in detail by analyzing high speed video images. It can be supposed that a certain amount of fuel vapor generated from the sand surface beneath a higher temperature region is transferred by the reverse flow to a lower temperature region ahead of the leading flame edge. Soon after arriving at the lower temperature region, the gas mixture is chilled and mist appears. The mist moves far from the leading flame edge, then diffuses outside of the reverse flow region. Similar mist behavior is observed repeatedly. Based on the mist behavior, the velocity of the reverse flow induced in the thin gas layex on the sand surface was inferred to be about $6 \mathrm{~cm} / \mathrm{s}$ in the case $\mathrm{U}=21.0 \mathrm{~cm} / \mathrm{s}$.

The horizontal distance $L$ from the leading flame edge to the separation point and the vertical distance $H$ from the sand surface to top edge of the reverse flow region were defined as the representative dimensions of the reverse flow region. Because it is difficult to measure $I$ and definitely, these values were examined repeatediy. Figure 4 shows the relations between these dimensions and $\mathrm{U}$ at a representative location on the tray. It can be seen on an average that $L$ is almost independent of $U$ and $H$ decreases with increase in $U$. The variation of $H$ with $U$ is found to be similar to that of the displacement thickness $\delta *$, as $\delta$ * is a representative value to indicate the low velocity layer on the sand surface where the reverse flow region can be formed. As U increases, the flame approaches the sand surface and the rate of heat transfer increases to keep the horizontal dimension of the reverse flow region. It is inferred that the reverse flow is induced by the thermal expansion of gas due to combustion at the leading flame edge and the evaporation of liquid fuel. caused by the heat transferred to the condensed phase near the leading flame edge. The latter phenomenon is considered to be effective for the formation of a stable reverse flow region even at a high free stream velocity.

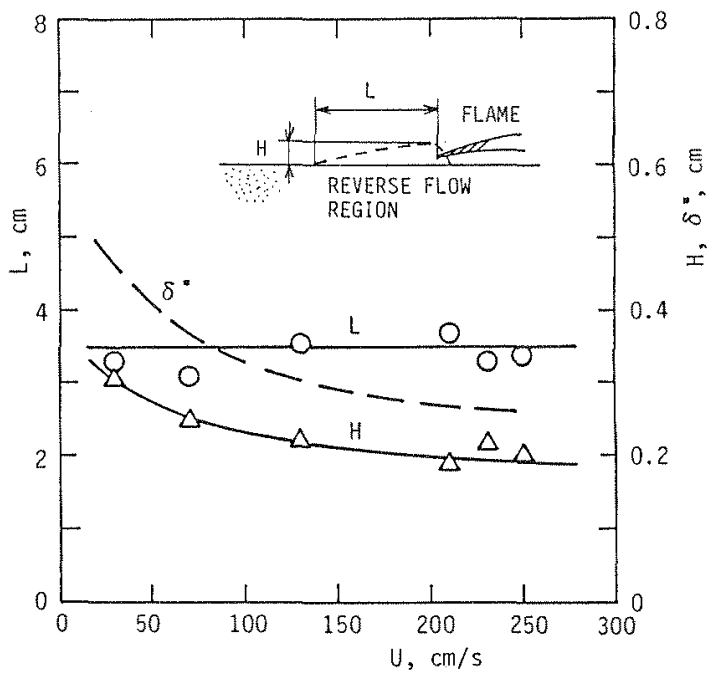

FIGURE 4. Relations between dimensions of the reverse flow region and free stream velocity. $\delta *$ : displacement thickness of the boundary layer without flame. $\mathrm{x}=80 \mathrm{~cm}, \mathrm{~T}_{i}=20^{\circ} \mathrm{C}$. 
In order to explore the behavior of the reverse flow, schlieren photographs of the leading flame edge were taken. Figure 5 shows a typical schlieren photograph and an illustration of the phenomena, where representative positions for indicating the behavior of the leading flame edge are shown. Although the flame is not seen clearly on the schlieren photograph, a temperature increasing region near flame zone can be observed clearly, the boundary of which is found to correspond to that where smoke streaks vanish (Figs. 2 and 3). When the free stream was higher than $150 \mathrm{~cm} / \mathrm{s}$, the schlieren image of the reverse flow could be observed on the sand surface in front of the leading edge of the temperature increasing region as seen in Fig. 5 (b). The behavior of the reverse flow was observed continuously by schlieren photography using a high speed video camera. Figure 6 shows position-time diagrams representing the behavior of the reverse flow and the leading flame edge at a high free stream velocity. The position $x 3$ of the leading flame edge is found to move slowly at a mean velocity of $0.026 \mathrm{~cm} / \mathrm{s}$ with slight fluctuations of 1.1 Hz. It can be seen that the reverse flow is formed continuously al.though the position $x 1$ of its leading edge fluctuates largely at nearly the same frequency as the leading flame edge. The mean distance from the leading flame edge to the leading edge of the reverse flow is about 1.5 $\mathrm{cm}$, which is about a half the dimension L measured based on the behavior of smoke streaks (Fig. 4). Since the shear flow between the reverse flow a.long the sand surface and the main air flow outside of the reverse flow region becomes intense as the free stream velocity increases, the flow field neax the leading flame edge becomes unstable and the leading flame edge fluctuates largely at a free stream velocity larger than $250 \mathrm{~cm} / \mathrm{s}$.

The velocity of the reverse flow induced in the thin gas layer on the sand surface was inferred from the behavior of smoke streaks, vapor mist, or schileren image. The variation of the reverse flow velocity $V_{r}$ with $U$

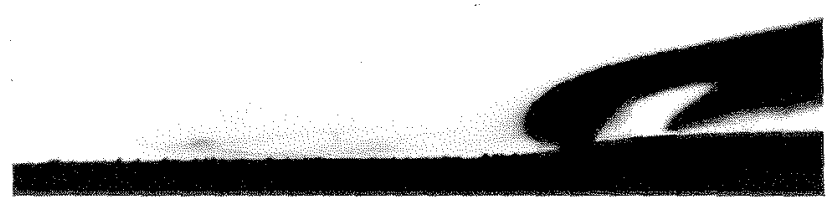

(a)
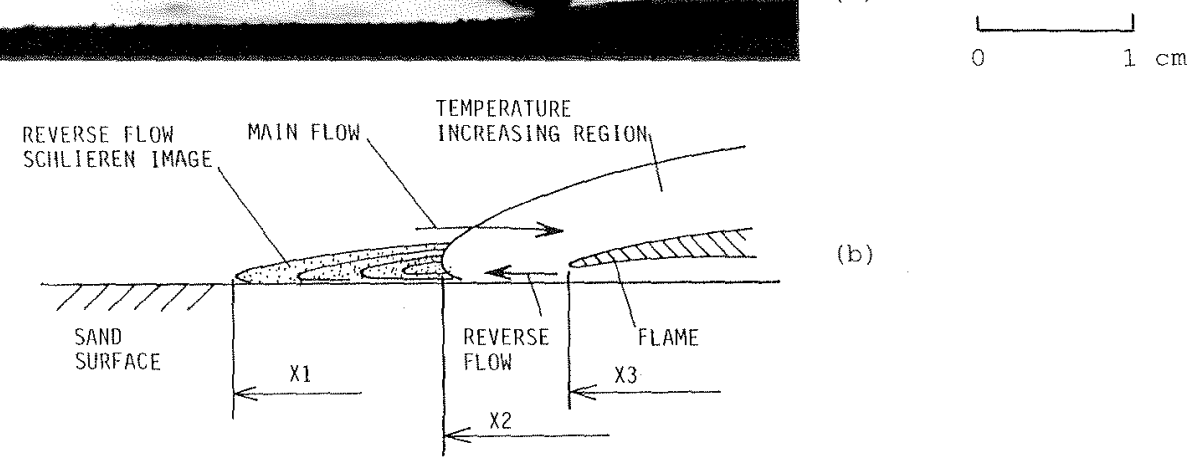

(b)

FIGURE 5. A typical schlieren photograph (U=210 cm/s, $\left.x=80 \mathrm{~cm}, \mathrm{~T}_{i}=20^{\circ} \mathrm{C}\right)$ and an illustration of the phenomena, where representative positions $x_{1}, x_{2}$ and $x 3$ are defined for indicating the behavior of the leading flame edge. 


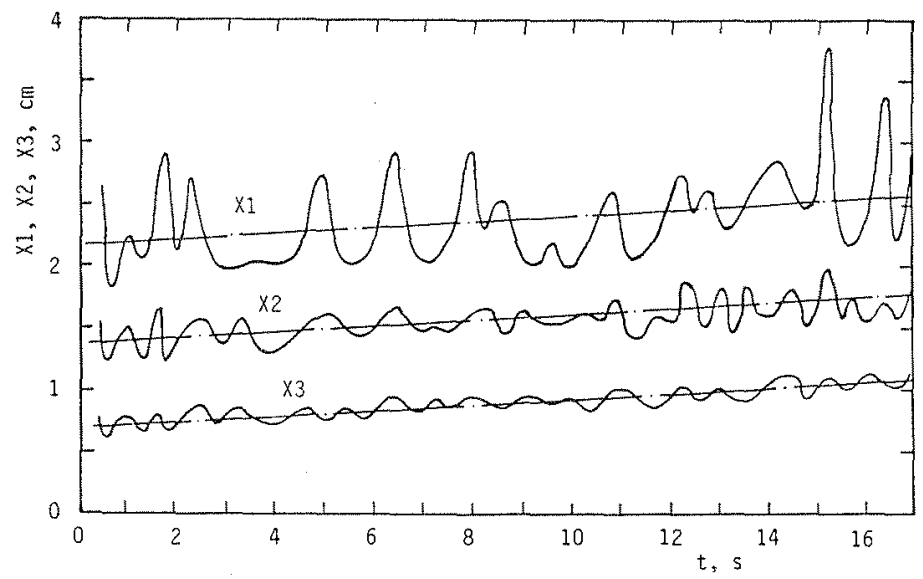

FIGURE 6. Position-time diagrams representing the behavior of the reverse flow and the leading flame edge. $\mathrm{U}=210 \mathrm{~cm} / \mathrm{s}, \mathrm{x}=80 \mathrm{~cm}, \mathrm{~T}_{i}=20^{\circ} \mathrm{C}$.

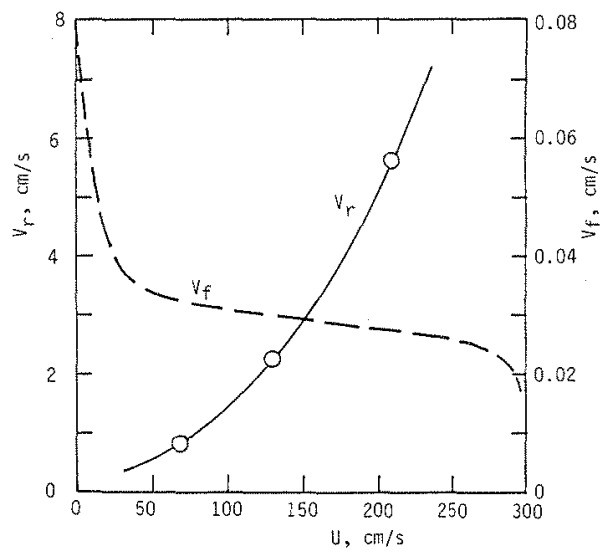

FIGURE 7. Variations of the reverse flow velocity and the flame spread rate with the free stream velocity. $\mathrm{T}_{i}=20^{\circ} \mathrm{C}$, the reverse Elow velocity was measured at $\mathrm{x}=80 \mathrm{~cm}$.

is shown in Fig. 7 together with that of the flame spread rate $V_{f}$. As U increases, $V$ increases. This reverse flow increase seems effective to keep the horizontal dimension of the reverse flow region even in a higher free stream. Since the stable reverse flow region is formed in a wide range of $U$, the flame can spread in the opposed air stream at a nearly constant speed independent of the reverse flow velocity. These facts imply that the reverse flow has no appreciable effect on the flame spread rate, although it is effective to form a stable reverse flow region which is necessary for the flame stabilization in the air stream. When 10 vol.\% of $n$-hexane was added to kerosene, the flame spread rate $V_{f}$ increased about 20 \% for the same free stream velocity $(210 \mathrm{~cm} / \mathrm{s})$ and no appreciable change in the behavior of the reverse flow could be observed. This fact also implies that the reverse flow has no appreciable effect on the flame spread rate. Since the behavior of the reverse flow scarcely changes in these cases, the vapor supply rate near the leading flame edge can be assumed to depend mainly on the fraction of the volatile 
components in fuel soaked sand. with the addition of n-hexane.

Role of reverse flow

For the flame spread over solids soaked with combustible liquids at sub-flash temperatures, two important processes should be necessary, which are similar to those for the flame spread over combustible solids or liquids at sub-flash temperatures. One is preheating of the combustible material ahead of the leading flame edge and the other is stabilization of the leading flame edge. The reverse flow accompanied a gas flow along the sand surface from the hot leading flame edge. Although the main mode of heat transfer for the flame spread can be inferred to be conduction or convection near the leading flame edge, the gas flow along the sand surface must assist the heat transfer to the unburned region to continue the flame spread. It is obvious that a slow gas stream region is necessary for the stabilization of a diffusion flame established over a flat plate. The reverse flow provides this slow gas stream region, through which gasified molecules as well as heat from the flame reaction zone would be transferred in the upstream direction and the leading flame edge could be stabilized. Thus, it is inferxed that the reverse flow takes an important role in the stable flame spread in an opposed air stream, although it has no appreciable effect on the flame spread rate in the limit of present experiments.

The mass transfer caused by the reverse flow in the region in front of the leading flame edge seems to be effective for increasing the flame spread rate or stabilizing the leading flame edge. Vaporized fuel. gas in front of the leading flame edge can be inferred to mix with the ambient gas and to flow into the flame reaction zone. If the concentration of the fuel. gas were enough for flame propagation, the flame would propagate upstream. Therefore, the concentration in front of the leading flame edge must be low although the reverse flow can be assumed to be to some extent effective in increasing the number of molecules at the flame reaction zone per unit time.

\section{CONCLUSIONS}

The behavior of the reverse flow in front of the leading flame edge spreading over kerosene-soaked sand in an air stream has been examined using a few flow visualization techniques, and the role of the reverse flow in the flame spread is discussed.

In a wide range of the free stream velocities $\mathrm{U}$ from 30 to $210 \mathrm{~cm} / \mathrm{s}$, a stable reverse flow region in front of the leading flame edge was observed clearly by smoke behavior, and its horizontal dimension $L$ was found to be almost independent of $\mathrm{U}$. Detalis of the reverse flow were visualized with a mist that generates in front of the leading flame edge. It is inferred that the reverse flow is induced by the thermal expansion of gas due to combustion at the leading flame edge and the evaporation of liquid fuel near the leading flame edge.

When $\mathrm{U}$ is larger than $150 \mathrm{~cm} / \mathrm{s}$, the schlieren image of the reverse flow can be observed, which represents distinctively the behavior of the reverse flow. It is seen that the reverse flow is formed continuousiy 
although its leading edge Eluctuates largely at the same sxequency (about $1.1 \mathrm{~Hz}$ ) as that of the leading flame edge.

As $U$ increases, the reverse flow velocity $V_{r}$ increases. The reverse flow is found to take an important role in the stable flame spread in an opposed air stream, although it has no appreciable effect on the flame spread rate in the limit of present experiments.

The reverse flow provides a slow gas stream region, which is necessary for the stabilization of a diffusion flame, through which gasified fuel molecules as well as heat from the reaction zone would be transferred in the upstream direction. However, the gasified fuel concentration in front of the reading flame edge must be low although the reverse flow can be assumed to be to some extent effective in increasing the number of molecules at the flame reaction zone per unit time.

\section{ACKNOWLEDGMENT}

The authors would like to express their sincere thanks to Messrs. T. Saeki, S. Sakata and T. Maki for their help in conducting experiments.

\section{REFERENCES}

1. Kaptein, M, and Hermance, C. E.: "Horizontal Propagation of Laminar Flames Through Vertically Diffusing Mixtures Above a Ground Plane," Sixteenth Symposium (International) on Combustion, The combustion Institute, pp.1295-1306, 1976.

2. Ishida, H.: "Flame spread over Fuel-soaked Ground," Fire Safety J., 10, 163-171, 1986.

3. Takeno, K. and Hirano, T.: "Flame spread over Porous Solid Soaked with a Combustibie Liquid," "Twenty-first Symposium (International) on Combustion, The Combustion Institute, pp.75-81, 1986.

4. Takeno, K. and Hirano, T.: "Behavior of Combustible Liquid Soaked in Porous Beds During Flame Spread," Twenty-second symposium (International) on Combustion, The Combustion Institute, pp. 1223-1230, 1988 .

5. Grassman, I. and Dryer, F.: "Flame Spreading Across Liquid Fuels," Fire Safety J., 3, 123-138, 1980.

6. Fernandez-Pel1o, A. C. and Hirano, T.: "Controlling Mechanisms of Flame Spread," Combustion Science and Technology, 32, 1-31, 1983.

7. Hirano, T., Suzuki, T., Sato, J. and ohtani, H.:"Flame spread over Crude oil Sludge," Twentieth Symposium (International) on Combustion, The Combustion Institute, pp.1611-1617, 1984.

8. Suzuki, T., Kudo, N., Sato, J., Ohtani, H. and Hirano, T.: "Flame Spread over Thin Layer of Crude Oil sludge," Fire Safety Science, Proceedings of the First International Symposium, Hemisphere, pp. 55-64, 1986 .

9. Suzuki, T. and Hirano, T.: "Flame Propagation Across a Liquid Fuel in an Air Stream," Nineteenth Symposium (International.) on Combustion, The Combustion Institute, pp.877-884, 1982.

10. Suzuki, T., Kawamata, M. and Hirano, T.: "Flame Spread over Fuel Soaked Sand in an opposed Air stream," Fire Safety science, Proceedings of the Second International Symposium, Hemisphere, pp. 199-208, 1989 . 